\title{
Effect of moisture content on the flowability of crushed ores
}

\author{
Francisco Cabrejos ${ }^{1, *}$ \\ ${ }^{1}$ Jenike and Johanson Chile S.A., Avda. Libertad 798, Office \#501, Viña del Mar, Chile
}

\begin{abstract}
In many mining and industrial processes where large quantities of non-degrading bulk materials such as crushed ores are handled, silos, hoppers, stockpiles and chutes are widely used because they are economical and reliable (if properly designed and operated). However, they are not free of trouble and may experience flow problems such as arching, ratholing, erratic flow, limited storage capacity, limited discharge flow rate, caking, segregation and/or flooding. Moisture content and fine particles significantly affect the flowability of most ores, increasing their cohesive strength and turning them more prone to these problems. The purpose of this article is to highlight a proven, scientific method that can be utilized to ensure reliable storage, flow and discharge of bulk solids in these equipment based on Jenike's flow-of-solids theory and laboratory testing. Knowledge of the flow properties of the material handled provides a design basis to ensure mass flow, avoid arching and prevent the formation of "ratholes". The effect of an increase in water content of the ore is discussed with experimental results.
\end{abstract}

\section{Introduction}

Today, bulk solids handling is one of the largest industrial activities in the world. According to the British Material Handling Board more than 16 billion tons of common and industrial materials were transported, handled, and stored in bulk during 2013, usually several times. Millions of tons of ores, concentrates, coal, flyash, fertilizers, agricultural products and salt are mined, handled, transported, stored, crushed, clasified, and/or processed every day of the year in many industries.

In the case of Chile, mining is the most important industrial activity in the country. Chile produced approx. 5.8 million tons of fine copper in 2013, which represents about $50 \%$ of our total exports. To produce 5.8 million tons of fine copper in one year, more than 2 million tons of ores must be mined, handled, loaded, transported, stored, crushed, clasified, milled and processed every day, not including the overburden and the low grade ores transported to dumps. Clearly, bulk solids handling is of vital importance to the nation's development.

Bulk solids are defined as an ensemble of many solid and discrete particles of different size and/or shape, but with the same common nature. For design purposes, it is not enough to simply define a bulk material by its name, origin, source or history. The main characteristics and flow properties will be described in this paper, including testing and standards available to properly characterize a bulk material from a solids handling viewpoint.

As opposed to liquids, bulk solids can hold shear stresses even being at rest, and they may also be cohesive and/or compressible, which explains why they behave so differently. An important characteristic of bulk materials is their ability to form a pile when particles are dropped from some height over a flat surface, forming a repose angle as shown in Figure 1.

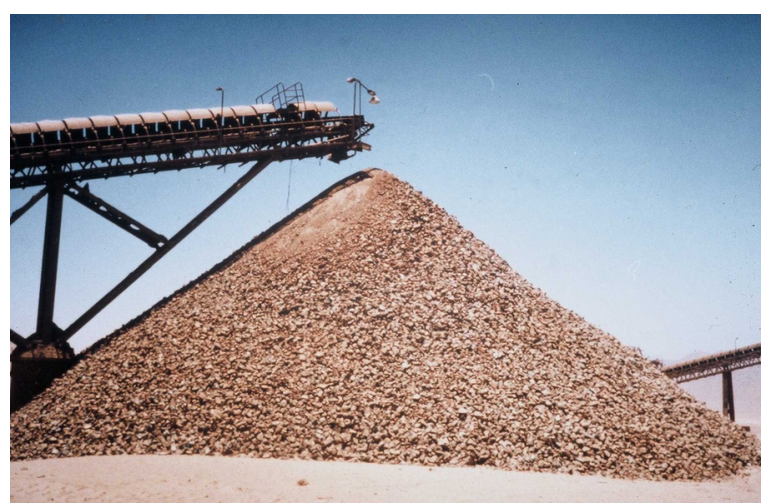

Fig. 1. Repose angle in a coarse ore conical stockpile [1].

\section{Characteristics of bulk solids}

From the viewpoint of flow, bulk materials may or may not gain cohesive strength when handled in stockpiles, silos, bins and hoppers depending on the combination of several factors. If the material does gain cohesive strength, then problems of arching or ratholing may occur - depending on the shape of the hopper, dimensions of the outlet, wall angles, wall liner, and the flow pattern developed by the bulk solid in the storage equipment (mass flow or funnel flow).

The flowability of most bulk solids and ores are affected by the following characteristics and parameters:

- Particle size and size distribution,

- Maximum particle size and content of fines,

- Moisture content,

- Storage time at rest and under pressure,

- Consolidating pressure (i.e. height of the pile or silo),

- Temperature and weather conditions,

- Presence of oils, clays, talcs and/or additives,

- Chemical and minerallurgical nature of the material. 
The size of the particles is one of the main characteristics of a bulk material from the viewpoint of handling, storage and transport. The most simple and economic technique to determine the size distribution widely used in industry for years - is sieving.

Another characteristic needed to describe a bulk material is particle density. This parameter corresponds to the real density of the material, i.e. its weight per unit volume, and it is measured by volumetric displacement in a calibrated tube. In the case of water-soluble materials, other liquids should be used such as acetone or alcohol. This parameter is required to estimate minimum transport velocity and pressure drop in pneumatic conveying, and for flow modeling with DEM.

The moisture content of a bulk material (dry basis) is defined as the weight of the surface or free water contained in the material $\left(\mathrm{W}_{\mathrm{w}}\right)$ over the weight of the sample material minus the weight of the surface or free water $\left(\mathrm{W}_{\mathrm{s}}\right)$, and is expressed as a percentage, as follows:

$$
M C=\frac{W_{w}}{W_{s}} \cdot 100 \%
$$

A small sample is dried in an oven at $110^{\circ} \pm 5^{\circ} \mathrm{C}$ until the material does not loose any more weight, based on the standard procedure given by ASTM D 2216. To determine the total moisture content of coal samples, standard ASTM D 3302 should be used.

This parameter strongly affects the flowability of bulk materials, may create arching and/or ratholing flow problems, and reduces the live storage capacity in silos and stockpiles, as will be described next.

\section{Flow properties of bulk solids}

About five decades ago, Dr. Andrew Jenike proposed a flow-of-solids theory to properly design silos, bins and hoppers [2]. This theory is based on the flow properties of the material handled, which can be determined in a laboratory at the expected operating conditions to be encountered in the plant. The main flow properties required to characterize a bulk solid include:

- Cohesive strength and internal friction,

- Wall friction and chute angle,

- Compressibility (bulk density) and permeability.

Tests should be performed on the minus 1/4" mesh fraction of a representative sample of the bulk solid $(100 \%-6.3 \mathrm{~mm})$ since typically this fine fraction is what governs the flow behavior of the whole material. Tests are often conducted at different moisture contents, and for continuous flow as well as for different storage times at rest, to determine how these parameters affect the material's flowability. Flow function tests (today standard ASTM D 6128 using Jenike's direct shear tester, or ASTM D 6773 using the rotational shear tester proposed by Dr. Dietmar Schulze) are used to determine the cohesive strength of a material and its flowability.

More details about other tests to determine wall friction and chute angles on different wall liners, compressibility and permeability can be found in [3].

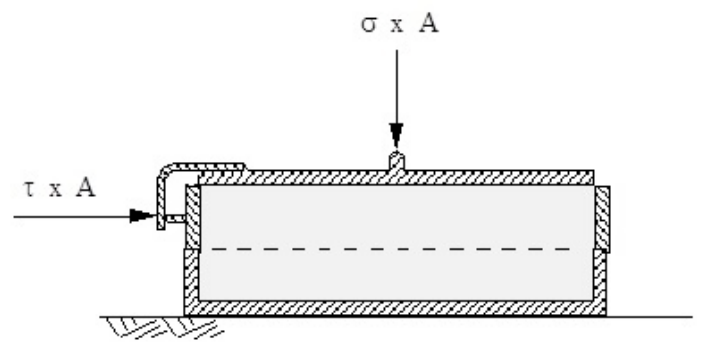

Fig. 2. Direct uniaxial shear test proposed by A. Jenike [2].

\section{Effect of moisture content}

As mentioned above, the moisture content of a bulk solid strongly affects its flowability, which in turn, increases its tendency to arch and/or rathole, leading to flow stoppages and loss of live storage capacity in storage equipment such as silos, hoppers, stockpiles and chutes.

\subsection{Arching}

Arching in a silo or hopper can be due to the size of the particles and/or to the cohesive nature of the material, mainly due to its moisture content. To avoid the problem of cohesive arching, the discharge outlet should be large enough and be designed following Jenike's theory [2] considering the cohesive strength of the material. Based on our experience with crushed ores tested in our laboratory over the years, Figure 3 shows schematically how the minimim outlet dimensions of a conical hopper increases with moisture content.

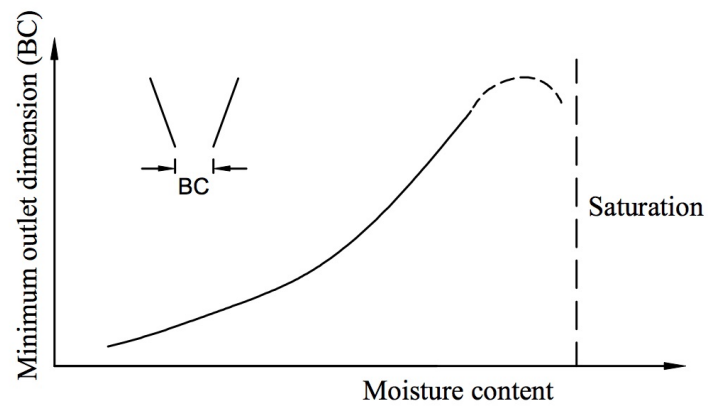

Fig. 3. Minimum outlet dimension of a conical hopper as a function of moisture content.

\subsection{Ratholing}

The formation of ratholes is typical in stockpiles and funnel flow silos and hoppers with small discharge outlets when handling cohesive materials, as shown in Figure 4. Ratholes may be stable or unstable. In the case of a stable rathole, the material "hangs up" and forms a steep, almost vertical wall, leading to flow stoppage and loss of live storage capacity. In the case of an unstable rathole, flow from the hopper may become erratic. As the rathole collapses, falling material impacts the hopper outlet and may cause a cohesive arch to form, thus stopping flow again. 
To avoid the problem of ratholing and to ensure reliable flow, mass flow hoppers should be used to expand the flow channel to a diameter greater than the critical rathole diameter. The critical rathole diameter is a function of the cohesive strength of the material, which in turn increases with moisture content, storage time at rest and consolidation pressure (effective head).

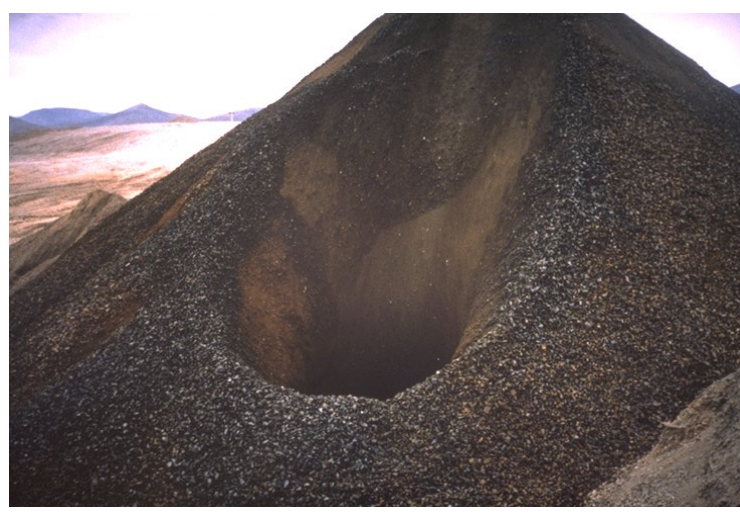

Fig. 4. Typical formation of a "rathole" in a stockpile.

\subsection{Cohesive strength}

Figure 5 shows the results of flow function instantaneous tests on a sample of the fine fraction of a crushed copper ore ( $100 \%$ minus 1/4"), tested at different levels of moisture content to determine how sensitive this material is to an increase in water content. Time tests (24-hours or more) could be also done to simulate the maximum storage time at rest and under pressure of the material in a silo, hopper or stockpile. This figure also includes the original classification proposed by Jenike [2], and it can be seen that this particular ore is easy-flowing if handled at $1 \%$ moisture and for instantaneous flow conditions but becomes cohesive at higher moisture levels.

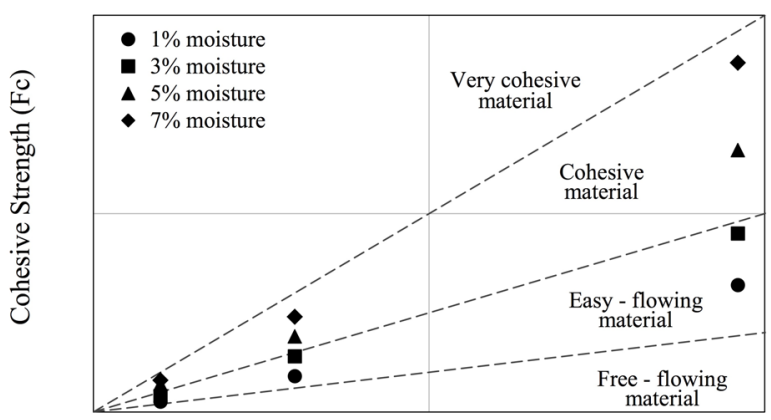

Consolidating Pressure $\left(\sigma_{1}\right)$

Fig. 5. Instantaneous flow function of a particular crushed copper ore (fines minus 1/4") tested at four moisture levels.

\subsection{Drawdown angle}

Gravity discharge tests illustrate the range of occurence for the repose angle $\left(\alpha_{R}\right)$ and the drawdown angle $\left(\alpha_{D D}\right)$ of a bulk material, as shown schematically in Figure 6. The repose angle is formed when discharging a material from some height and onto a flat surface, while the drawdown angle corresponds to the slope of the remaining walls of material left after gravity discharge ceases. Both angles are measured from the horizontal and are due to the ability of bulk solids to withstand shear stresses (liquids cannot).

As an example, Figure 7 shows the drawdown angle formed by the fine fraction minus $1 / 4$ " of a crushed copper ore at $1 \%$ moisture (top), i.e. just a few degrees steeper than the repose angle, and about $70^{\circ}$ at $5 \%$ moisture (bottom). The live storage capacity of stockpiles and flat bottom silos strongly depends on this parameter, which in turn depends on the moisture content and the amount of fine particles in the ore.

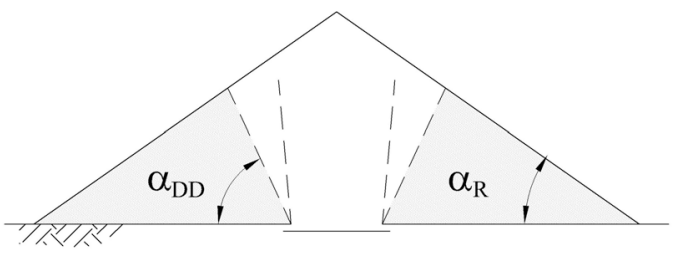

Fig. 6. Repose and drawdown angles of a bulk material.
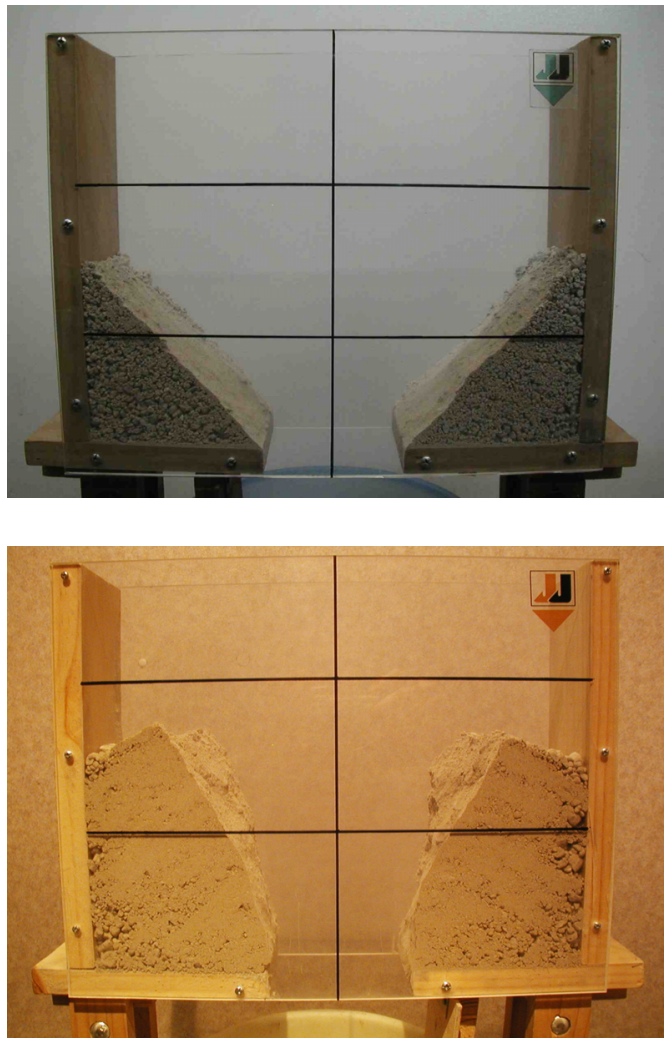

Fig. 7. Drawdown angle of a crushed copper ore tested at $1 \%$ and $5 \%$ moisture in a slice $2 \mathrm{D}$ model of a flat bottom bin.

\subsection{Wall friction and chute angle}

Wall friction tests should be performed on different types of wall liners to determine the minimum angle for mass flow. The coefficient of friction is also required for bin loads and structural design of silos, hoppers and feeders. Chute tests should be performed on different types of wall liners to determine the minimum slope of a plane surface to maintain flow of material after impact. 
Along with the wall friction angle, this is an important parameter in the design of sliding chutes and belts, to prevent adhesion problems between the bulk material and the wall liner selected, as illustrated in Figure 8.

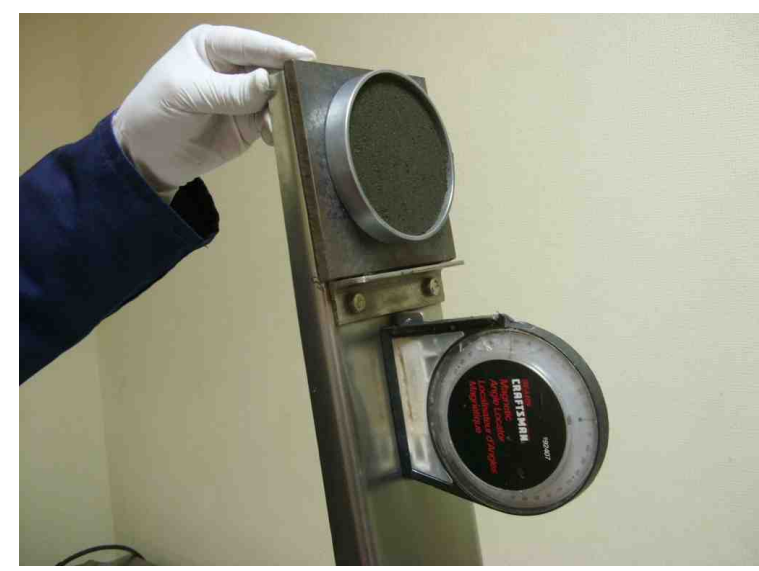

Fig. 8. Adhesion of copper concentrate at $10 \%$ moisture onto a plate of carbon steel.

\subsection{Moisture content as function of particle size}

Some interesting results of a test done with a primary crushed copper ore handled in a local mine are given in the next figures. Figure 9 shows the cumulative sieve analysis of the ore while Figure 10 the moisture content of each fraction of the ore tested. The moisture content of the complete sample is $3.8 \%$, but clearly, the fines contain a higher proportion of water due to their larger surface area, as compared with the coarser particles.

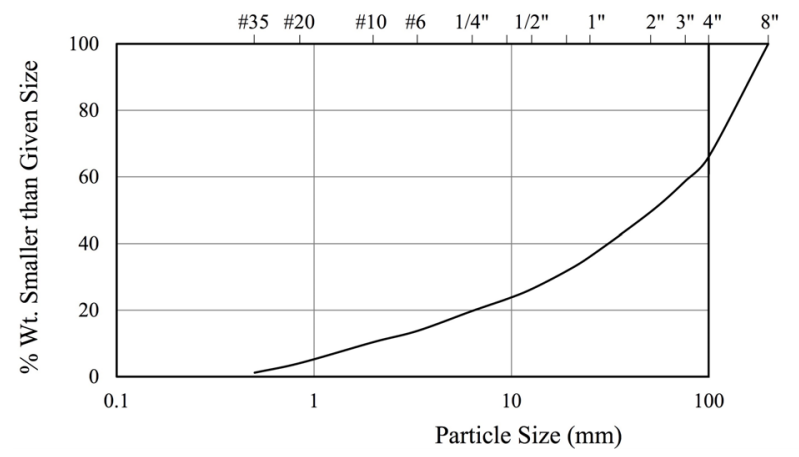

Fig. 9. Particle size distribution of a primary crushed ore.

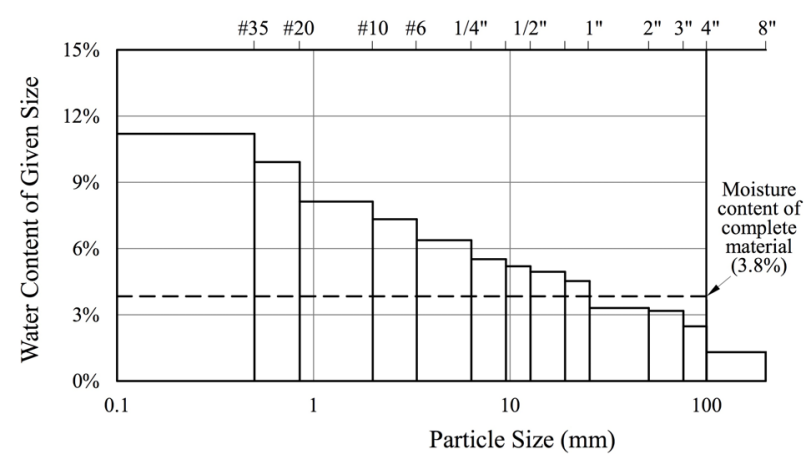

Fig. 10. Moisture content of the primary crushed ore shown in Figure 9 (determined per sieve size).

\subsection{Relationship for water content of the fines}

The test described next was developed by $\mathrm{J} \& \mathrm{~J}$ engineers to better understand how the water gets distributed between the fine and coarse particles in a sample of crushed ore. Fines are defined here as the fraction below mesh 1/4" as per ASTM D 6128. A sample of $50 \mathrm{kgs}$. of dry ore containing a known percentage of fines and a top size of 4" was placed in a drum. A given amount of water was sprayed on the ore surface and the moisture content of the full size ore was calculated using equation (1). Next, the drum was closed, rotated during 3 days, and the moisture content of the fines was determined.

The test was repeated varying the fines content of the ore, and the complete results are summarized in Figure 11. For example, the moisture content of the fine fraction (minus 1/4") of a full size ore with $25 \%$ of fines is about 2 times larger as compared to the full size ore.

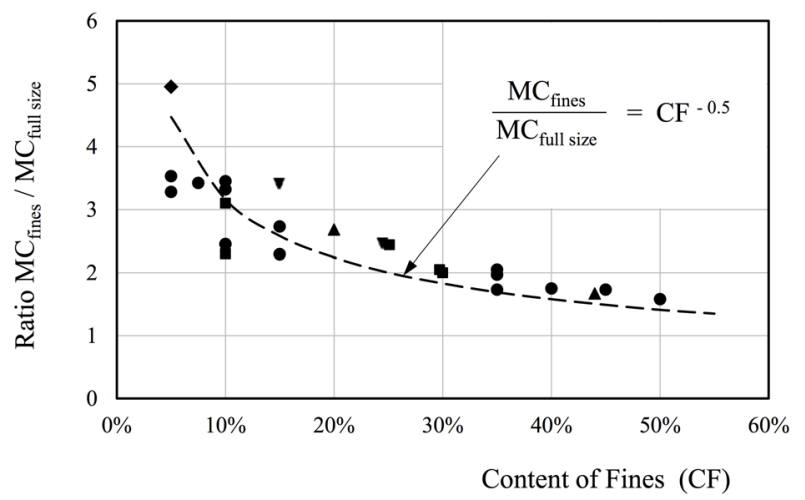

Fig. 11. Effect of moisture content of the minus $1 / 4$ " fraction of the ore as a function of moisture and content of fines of the ore.

\section{Conclusions and recommendations}

The moisture content strongly affects the flowability of most crushed copper ores, increasing their cohesive strength and turning them more prone to create flow problems such as arching and ratholing.

Fine particles of a crushed ore have a higher moisture content - as compared with the coarser particles - due to their larger surface area. This article presented the results of a simple test to determine how much water this fine fraction could contain, based on the percentage of fines (minus 1/4") and the moisture content of the full size ore.

Finally, testing provides the best method to characterize a bulk material and its handling properties for proper equipment and system selection, design and operation of silos, hoppers, stockpiles and chutes [3].

\section{References}

1. F. Cabrejos and A. Del Campo, Ensure Reliable Flow - How to Design Gravity Reclaim Stockpiles, BSH, Vol. 29, No. 6 (2009), pp. 350-355

2. A. Jenike, Storage and Flow of Solids, University of Utah Engineering Experiment Station, Bulletin No. 123, November 1964

3. www.jenike.com 